\section{Çocuklarda Hymenolepis diminuta Araştırılması: Daha Önce Aynı Köyde Karşılaşılan Bir Vaka Üzerine}

\author{
Screening Children for Infection with \\ Hymenolepis diminuta due to a Previous Case \\ Reported from the Same Village
}

\section{Özet}

Amaç: Bu çalışmada, daha önce Düzce'deki Kemerkasım köyünde yaşayan 21 aylık bir erkek çocukta Hymenolepis diminuta enfeksiyonu saptanması nedeniyle, aynı bölgede yaşayan tüm çocuklarda bu parazitin varlığının araştırılması amaçlanmıştır.

Gereç ve Yöntemler. Köyde yaşayan ve yaşları 3 ay ila 11 yıl arasında değişen 83 çocuğun hepsi çalışmaya dahil edilmiştir. Çocukların ailelerine ulaşımış ve çalışmanın amacı anlatılmıştır. Çaıısmaya katılmayı kabul eden ailelere sözlü anket uygulanmış, çocuklardan alınan gaita örnekleri aynı gün laboratuvarda makroskobik ve mikroskobik olarak incelenmiştir. Mikroskobik incelemede direkt taze preparat ve konsantrasyon yöntemi kullanıımıştır.

Bulgular. Hiçbir çocukta Hymenolepis diminuta saptanmamış, ancak dört çocukta Giardia intestinalis enfeksiyonu tespit edilmiştir.

Tartışma ve Sonuç: Sonuç olarak bir çocukta daha önce Hymenolepis diminuta saptanmış olması nedeniyle aynı çevrede yapılan taramada bu türden yeni bir vakaya rastlanmamıştır. Enfeksiyonun bu bölgede sporadik olduğu düşünülmüştür.

Anahtar Kelimeler. Hymenolepis diminuta; artropod; çocuklar; Düzce Kemerkasım köyü

\begin{abstract}
Aim: We previously reported that we detected Hymenolepis diminuta infection in a 21-monthold boy in the the Kemerkasım village in the Düzce province of Turkey. In this study, we aimed to screen all of the children in the same region for infection with Hymenolepis diminuta.

Material and Methods: All of the eighty-three children who lived in this village and were aged between 3 months and 11 years were included in the study. The children's families were reached and informed about the aim of the study. The families who agreed to participate in the study were surveyed verbally, and the stool samples obtained from the children were examined macroscopically and microscopically within the same day. Fresh preparation and concentration methods were used for the microscopic examination.

Results: Hymenolepis diminuta was not found in any of the children, but four children were found to have been infected with Giardia intestinalis.

Discussion and Conclusion: No new cases were detected during the screening for infection with Hymenolepis diminuta, performed due to a previous case reported in the same region; and we have concluded that Hymenolepis diminuta infection is sporadic in this region.
\end{abstract}

Key Words: Hymenolepis diminuta; arthropod; children; Kemerkasım village in Duzce
Özge Kılınçel',

Aytolun Aytan², Onur Efe Çelik², Nida Kılıç ${ }^{1}$, Cihadiye Elif Öztürk'

Düzce Üniversitesi Tıp Fakültesi Tıbbi Mikrobiyoloji Anabilim Dalı, Düzce

2 Düzce Üniversitesi Tıp Fakültesi, Düzce
Geliş Tarihi /Received : 18.08.2015 Kabul Tarihi /Accepted: 08.10.2015

Sorumlu Yazar/Corresponding Author Arş. Gör. Dr. Nida Kılıç Düzce Üniversitesi Tıp Fakültesi

Tıbbi Mikrobiyoloji Laboratuvar Konuralp-Düzce

E-mail:nidakilic87@gmail.com 


\section{Gíiş}

İnsanlarda nadiren Hymenolepis diminuta enfeksiyonu görülür. Hymenolepis diminuta hijyen şartlarının kötü olduğu yerlerde bulunan ve ender rastlanan bir sestottur (1). Hymenolepis diminuta'nın hayat döngüsünde kemirgenler, özellikle de fareler, hem kesin konak hem de rezervuar olarak rol oynar. Artropodlar ara konak olarak yer almaktadır. Parazitin yumurtaları artropodlar tarafından alındığı zaman sistiserkoit dönem oluşmaktadır $(2,3)$. Enfeksiyon, kemirgenlerde sistiserkoit larvaları taşıyan artropodların yenmesiyle ortaya çıkarken, insanlarda ise özellikle çocuklarda artropodların yanlışılıkla ağız yoluyla alınması sonucunda meydana gelmektedir. $H$. diminuta'nın, farelerin çoğunlukla tükettikleri yiyecek olan tahıl ve kuru gıdaların saklandığı depo ve ambarlarda da sıkça bulunmasından dolayı, enfeksiyonun yayılışında bu g1daların da rolünün olabileceği düşünülmektedir (4). Ağız yoluyla alınan sistiserkoit larvalar ince bağırsakta erişkin formlarına dönüşmekte ve yumurtaları dışkıda bulunmaktadır. Dolayısıyla dışkıda yumurta bulmak enfeksiyona işaret etmektedir (5). Ayrıca $H$. diminuta enfeksiyonunun zoonoz bir hastalık olması nedeniyle, özellikle fare gibi kemirgen laboratuvar hayvanlarıyla çalışanların karşı karşıya olduğu enfeksiyon riski önemlidir (6).

Bu çalışmada, 2015 yılında Düzce’nin Kemerkasım köyünde yaşayan 21 aylık bir çocukta rapor ettiğimiz H. diminuta enfeksiyonunun ardından, aynı bölgedeki tüm çocuklarda bu parazitin varlığının araştırılması amaçlanmıştır (7).

\section{GEREÇ VE YÖNTEMLER}

Çalışmamıza Düzce'nin Kemerkasım köyünde yaşayan ve yaşları 3 ay ila 11 yıl arasında değişen tüm çocuklar dahil edilmiştir. Seksen üç çocuğun ailelerine ulaşılmış ve çalışmanın amacı anlatılmıştır. Çalışmaya katılmayı kabul eden ailelere sözlü anket uygulanarak, çocukların yaşı, cinsiyeti, evin yakınında ahır olup olmadığı ve böcek, toprak, çiğ tahıl ve çiğ et yeme öyküleri sorgulanmıştır. Çocuklardan alınan gaita örnekleri aynı gün laboratuvarda makroskobik olarak değerlendirilmiş ve daha sonra lügol eriyiği ile taze preparat ve Fülleborn doymuş tuzlu su flotasyon tekniği kullanılarak mikroskobik olarak incelenmiştir (8).

\section{BULGULAR}

Ailelerine ulaşılan toplam 83 (49 erkek, $34 \mathrm{kız}$ ) çocuk çalışmaya katılmıştır. Çocukların yaşları; minimum 3 ay, maksimum 11 yıl, yaş ortalaması 5,7 2 2,9 olarak hesaplanmıștır. Çocukların 65’i (\%78’i) ahıra yakın evlerde yaşarken, 7 'sinde $(\% 8,4)$ böcek yeme, 12 'sinde $(\% 14,4)$ toprak yeme, 23 'ünde $(\% 27,7)$ çiğ tahıl yeme ve 1 'inde $(\% 1,2)$ çiğ et yeme öyküsü saptanmıştır.

Alınan dışkı örnekleri makroskobik ve mikroskobik olarak incelenmiştir. Hiçbirinde $H$. diminuta saptanmamış, ancak $4(\% 4,8)$ çocukta G. intestinalis enfeksiyonu tespit edilmiştir. Bölgenin aile hekimine ulaşılarak çocukların tedavileri planlanmıştır.

\section{TARTIŞMA}

Hymenolepis diminuta özellikle kemirgenlerde, nadiren de insanlarda enfeksiyona neden olan bir sestottur. İnsanlara infektif larvaları bulunduran böceklerin yutulması ya da $H$. diminuta yumurtaları ile kontamine yiyecek ve suların tüketilmesi yoluyla bulaşmaktadır. Klinik olarak genellikle asemptomatik olmakla birlikte, hafif abdominal ağrı ve bol dışkılama semptomlarıyla da karşımıza çıkabilmektedir. Ağır enfeksiyon durumlarında iştahsızlık, karın ağrısı, diyare, anal kaşıntı, baş ağrısı, sinirlilik gibi semptomlar görülebilmektedir. $H$. diminuta ile enfeksiyonun laboratuvar tanısı dışkıda 60-80 $\mu \mathrm{m}$ boyutlarında, altı çengelli tipik yumurtaların görülmesi ile konmaktadır $(9,10)$.

Farklı popülasyonlar üzerinde yapılan epidemiyolojik çalışmalarda $H$. diminuta ile parazitoz oranları $\% 0,001-5,5$ arasında rapor edilmiştir (2). Hindistan'da yapılan bir toplum tarama çalışmasında 8.000 gaita örneği incelenmiş ve 20 adet $H$. diminuta vakası tespit edilmiştir (11). Türkiye'de Gaziantep ilinde yapılan bir araştırmada 5.453 gaita örneği incelenmiş, 813’ünde $(\% 14,91)$ bir veya birden fazla parazit saptanmış, ancak $H$. diminuta yumurtasına rastlanmamıştır (12). Malatyalı ve ark. 730 ilköğretim öğrencisinin gaitasını incelemiş, 201'inde çeşitli parazitlere ait kist ve yumurtalara rastladıklarını ama $H$. diminuta tespit etmediklerini bildirmişlerdir (13).

Dünyanın her bölgesinden sporadik $H$. diminuta enfeksiyonları bildirilmektedir (1-4). H. diminuta en- 
feksiyonu kötü hijyen koşullarıyla ilişkilidir. Çocuklar $H$. diminuta ile enfekte olma oranı erişkinlere göre daha yüksektir (1).

Bizim çalışmamızda daha önce bu köyde yaşayan 21 aylık bir çocukta saptanan $H$. diminuta enfeksiyonu nedeniyle, aynı bölgede benzer kötü hijyen koşullarında yaşayan çocuklarda bu parazitin varlığı araştırılmış, ancak çocukların hiçbirinde $H$. diminuta saptanmamıştır. Enfeksiyonun bu bölgede sporadik olduğu düşünülmüş ve bölgenin parazit epidemiyolojisi hakkında bilgi sahibi olunmuştur.

Bu çalışma sonucunda, Düzce'de daha önce yapılan çalışmalarda olduğu gibi, G. intestinalis enfeksiyonuna rastlanmıştır. Öztürk ve arkadaşlarının Düzce’de farklı zamanlarda ve farklı bölgelerde yaptığı çalışmalarda $\% 10,4$ ve $\% 14,7$ oranlarında $G$. intestinalis enfeksiyonu bildirilmiştir $(14,15)$. Enfeksiyon oranlarının daha az bulunmasının, incelenen çocuk sayısının daha az olması ile ilişkili olduğu düşünülmüştür.

\section{SONUÇ}

Bölgemizde daha önce bir vaka saptanmı̣ olan köyde yaşayan hiçbir çocukta (hatta tedavisi sonrasında aynı çocukta da) H. diminuta enfeksiyonuna rastlanmamıştır.

\section{KAYNAKLAR}

1. Tiwari S, Karuna T, Rautaraya B. Hymenolepis diminuta infection in a child from a rural area: a rare case report. J Lab Physicians. 2014;6(1):58-9.

2. Tena D, Simón MP, Gimeno C, Pomata MTP, Illescas S, Amondarain I, et al. Human infection with Hymenolepis diminuta: case report from Spain. J Clin Microbiol. 1998;36(8):2375-6.

3. Marangi M, Zechini B, Fileti A, Quaranta G, Aceti A. Hymenolepis diminuta infection in a child living in the urban area of Rome, Italy. J Clin Microbiol. 2003;41(8):3994-5.

4. Rohela M, Ngui R, Lim YA, Kalaichelvan B, Wan Hafiz WI, Mohd Redzuan AN. A case report of Hymenolepis diminuta infection in a Malaysian child. Trop Biomed. 2012;29(2):224-30.
5. Karuna T, Khadanga S. A case of Hymenolepis diminuta in a young male from Odisha. Trop Parasitol. 2013;3(2):145-7.

6. Beyhan YE, Gürler AT, Bölükbaş CS, Açıcı M, Umur Ş. Bazı laboratuvar hayvanlarında nekropsi ve dışk bakısı ile saptanan helmintler. Türkiye Parazitol Derg. 2010;34(2): 98-101.

7. Kılınçel Ö, Öztürk CE, Gün E, Öksüz Ş, Uzun H, Şahin İ, Kılıç N. Nadir bir olgu olarak küçük bir çocukta Hymenolepis diminuta enfeksiyonu. Mikrobiyol Bul. 2015;49(1):135-8.

8. Ministry of Agriculture, Fisheries and Food; Agricultural Development and Advisory Service. Manual of Veterinary Parasitological Laboratory Techniques, Technical Bulletin No. 18, Her Majesty's Stationery Office, London. 1977.

9. Win W, Allen S, Janda W, Koneman E, Procop G Schrechenberger P, et al. Koneman's Color Atlas and Textbook of Diagnostic Microbiology, 6th ed. Philadelphia: Lippincott Williams \&Wilkins; 2006: 1285-6.

10. Korkmaz M. Barsak Helmintleri. Ankem Dergisi. 2006;20(2):170-6.

11. Chandler AC. The distribution of $\mathrm{H}$. diminuta infection in India and discussion of its epidemiological significance. Indian J Med Res. 1927;14:973-94.

12. Ekşi F, Doğan Y, Özdemir G, Zer Y, Bayram A, Karslıgil T. Gaziantep Üniversitesi Tıp Fakültesi Hastanesi'nde bir yıllık sürede gaita örneklerinde saptanan bağırsak parazitlerinin dağılımı. Fırat Tıp Derg. 2013;18(4):2358.

13. Malatyalı E, Özçelik S, Çeliksöz A, Değerli S, Yıldırım D. Şehir, ilçe ve köy ilköğretim okulu öğrencilerinde bağırsak parazitleri görülme sıklı̆̆ı. Türkiye Parazitol Derg. 2008;32(1):54-8.

14. Oztürk CE, Sahin I, Yavuz T, Oztürk A, Akgünoğlu M, Kaya D. Intestinal parasitic infection in children in postdisaster situations years after earth quake. Pediatr Int 2004;46(6):656-62.

15. Öztürk CE, Altınöz A, Göçmen Ş, Özaras F, Çalışkan E, Karadağ G, et al. Dışkıda parazit aranmasında taze preparat incelemesi ile bir konsantrasyon yönteminin araştırılması. 6. Ulusal Tanısal ve Moleküler Mikrobiyoloji Kongresi. Ankara: 2010:173. 